\title{
PROPOSTA DE IMPLEMENTAÇÃO DE UM CATÁLOGO VIRTUAL: ESTUDO DE CASO NA EMPRESA MINAS D' OURO FOLHEADOS LTDA
}

\section{ARTIGO ORIGINAL}

OLIVEIRA, Davi Thiago dias de ${ }^{1}$, MARTINS, Neiva de Alcantara ${ }^{2}$, MARTINS, Yuri Rocha $^{3}$, ROBERTO, José Carlos Alves ${ }^{4}$, ALMEIDA, Victor da Silva ${ }^{5}$

OLIVEIRA, Davi Thiago dias de. Et al. Proposta de implementação de um catálogo virtual: estudo de caso na empresa Minas d' Ouro Folheados Ltda. Revista Científica Multidisciplinar Núcleo do Conhecimento. Ano. 06, Ed. 10, Vol. 05, pp. 148-167. Outubro 2021. ISSN: 2448-0959, Link de acesso: https://www.nucleodoconhecimento.com.br/administracao/catalogo-virtual, $\quad$ DOI: 10.32749/nucleodoconhecimento.com.br/administracao/catalogo-virtual

\section{RESUMO}

No aspecto estratégico todas as empresas precisam passar por um processo de avaliação de seu ambiente, identificando oportunidades que possam projetar o seu negócio para um futuro de sucesso. A tecnologia penetrou em quase todos os negócios e, com ela, o marketing eletrônico, melhorando o alcance e a eficácia da comunicação com o público-alvo e identificando consumidores em potenciais. Este estudo de caso, tem como objeto de estudo a microempresa Minas de Ouro Folheados Ltda, que atua no segmento de artigos de joalheria, originou-se através do diagnóstico organizacional onde identificou-se a área de marketing como a de pior desempenho. Tem como questão norteadora: como a implementação de um

\footnotetext{
${ }^{1}$ Graduanda do curso de Administração.

${ }^{2}$ Graduando do curso de Administração.

${ }^{3}$ Graduando do curso de Administração.

${ }^{4}$ Orientador. Mestre em Engenharia de produção. Especialista Logística empresarial. Graduado em Administração com Ênfase em Marketing.

${ }^{5}$ Coorientador. Mestre em Engenharia de Processos. Pós-Graduando em Neuropsicopedagogia Institucional. Especialista em Gestão Estratégica de RH. Graduado em Administração e Pedagogia.
}

RC: 99329

Disponível em: https://www.nucleodoconhecimento.com.br/administracao/catalogovirtual 
catálogo virtual pode contribuir para o aumento das vendas e captação de novos clientes? O objetivo geral deste trabalho é identificar quais metodologias podem ser adotadas para contribuir com o processo de vendas e captação de novos clientes através de um catálogo virtual, juntamente com os objetivos específicos onde buscou-se demonstrar como a criação de um catálogo digital, a acuracidade no setor de estoque e o treinamento de revendedores pode contribuir para o aumento nas vendas e prospecção de novos clientes, além de identificar plataformas comerciais para a divulgação de produtos, prospecção de clientes através do marketing direto visando alavancar as vendas, oferecendo material de apoio digital para os seus revendedores que intermediam a venda direta ao cliente final, visto que, precisa-se fidelizar os seus clientes e adquirir novos. A metodologia adotada foi a pesquisa exploratória através da revisão de literatura e estudo de caso. Por fim, concluímos que as principais indicações foram a aplicação das ferramentas de qualidade $5 \mathrm{w} 2 \mathrm{~h}$ e curva abc que contribuíram para definir os parâmetros de como deveria discorrer o caminho para a resolução de problemas e o apontamento das soluções que deverão satisfazer as necessidades da organização. Espera-se que a introdução das ações interventivas alavanque as vendas através de treinamento para os revendedores e maior visibilidade na divulgação dos produtos por meio da criação de um catálogo digital, conforme análise realizada in loco.

Palavras-chave: Metodologias estratégicas, Revendedores, Clientes, Processo de vendas, Inventário.

\section{INTRODUÇÃO}

O referido artigo trata-se do estudo de caso realizado na Minas d' Ouro Folheados Ltda. Consiste em uma empresa do segmento de semijoias que, por meio do diagnóstico organizacional, identificou baixo índice de vendas, desta forma, foi visto a carência no departamento de marketing e na adequação da estrutura organizacional quanto aos controles da produção. Com isso, propôs-se a criação de um novo canal de divulgação on-line, um catálogo digital, para alavancar as vendas e a eficácia da comunicação com o público-alvo. Oferecendo apoio para seus

RC: 99329

Disponível em: https://www.nucleodoconhecimento.com.br/administracao/catalogovirtual 
revendedores com o intuito de fidelizar e captar novos clientes a cada lançamento de Coleções de Joias.

Objetiva-se demonstrar como a criação de um catálogo digital, a acuracidade no setor de estoque e o treinamento de revendedores podem contribuir para o aumento nas vendas e prospecção de novos clientes. Com a aplicação de ferramentas estratégicas do marketing como $5 \mathrm{~W} 2 \mathrm{H}$ e a curva $A B C$, a pergunta norteadora do presente trabalho será: como a implementação de um catálogo digital poderá contribuir para alavancar as vendas e a captação de novos clientes?

A metodologia de pesquisa aplicada no decorrer do presente trabalho, a partir da aplicação estratégicas, como a curva $A B C$ no gerenciamento do estoque, e a aplicabilidade da ferramenta $5 \mathrm{~W} 2 \mathrm{H}$ no plano de treinamento com técnicas de vendas para os revendedores e na identificação dos materiais nos estoques, irão aumentar a produção de novas peças e alavancar o processo de vendas e captação de novos clientes.

Com a aplicação do diagnóstico espera-se um aumento nas vendas, com a eficácia do canal digital, e comprometimento dos revendedores para alcance de metas. Gerando material de apoio com mais visibilidade na divulgação dos produtos, por meio do catálogo digital, conforme análise realizada in loco.

\section{REVISÃO BIBLIOGRÁFICO}

Como bem nos assegura Marconi e Lakatos (2017), pode-se dizer que a pesquisa bibliográfica é um tipo de produção científica baseada na coleta de dados de forma crítica e aprofundada das etapas de investigação, distingue-se da leitura corrente ou de referência, pois é feito de maneira profunda e exaustiva, e lida com ocorrências ou fatos reais.

Como bem nos assegura Vergara (2016), pode-se dizer que o referencial teórico é um tipo de pesquisa aprofundada sobre determinado tema, tomando como 
referência a contextualização de outros autores, a fim de oferecer consistência na construção de hipóteses e suposições que sejam adequadas à solução do problema.

A fundamentação teórica consiste em apresentar um breve resumo da literatura existente sobre um determinado tema, buscando a visão de outros autores para levantar uma análise técnica a sua pesquisa. Buscou-se apresentar, neste trabalho, autores clássicos já consagrados da administração que poderiam contribuir de forma pertinente com suas posições teóricas para a argumentação de nossa pergunta problema.

\subsection{GESTÃO ESTRATÉGICA}

Lazonick (2012) explica que para exercer o controle estratégico na alocação dos recursos, o gestor deve ter um profundo conhecimento das capacidades produtivas atuais e potenciais dos recursos presentes.

Para Kotler e Armstrong (2014), uma visão clara, estável e elevada é capaz de prover direção e impactar positivamente sua capacidade de prosperar no ambiente, através da obtenção de resultados favoráveis para o negócio.

A gestão estratégica, quando implantada da forma correta, assegura o crescimento da empresa por meio da adequação contínua das estratégias realizadas, ou seja, antecipa às mudanças que poderão ocasionar riscos para a organização. Além disso, a gestão estratégica visa adequar a participação de cada nível da empresa, para que haja o envolvimento coletivo no processo decisório das estratégias.

\subsection{GESTÃO DE ESTOQUE}

Conforme o autor Paoleschi (2014), inventariar os produtos é essencial para manter a acuracidade dos saldos do departamento de estoque. O inventário de materiais só pode ser feito depois que todos os itens estiverem identificados e guardados em seus devidos lugares, a tolerância entre a diferença do estoque no sistema ERP e o físico deve ser zero.

RC: 99329

Disponível em: https://www.nucleodoconhecimento.com.br/administracao/catalogovirtual 
De acordo com os autores Martelli e Dandaro (2015), o estoque não é apenas os produtos que estão armazenados nos depósitos, mas também os produtos que estão visíveis nas prateleiras em exposição para o cliente.

A gestão do estoque é fundamental, pois, caso haja alguma necessidade de correção por conta de algum desvio, haverá tempo hábil para o processo produtivo não ser afetado e não correr o risco de não atender o cliente e garantir a quantidade programada para o cliente.

Desta forma, essa metodologia garante o controle das semijoias e a segregação das peças por coleção ou lançamentos, isto é, o gestor do estoque poderá saber quais e quantas semijoias estarão disponíveis para os clientes naquele momento, de modo que, se alguma semijoia for retirada sem necessidade ou não puder ser encontrada no estoque, sua falta logo será notada pela liderança que poderá tomar decisões mais assertivas e eficientes. Vale ressaltar que a gestão do estoque não tem impacto somente no nível operacional, ela também auxilia nos processos estratégicos como, por exemplo, na elaboração do planejamento financeiro da empresa.

Por isso, o controle e o planejamento do estoque devem ser revisados periodicamente, para assegurar os efeitos da acuracidade dos produtos armazenados. Assim, caso haja algum desvio, poderá ser tratado de forma mais rigorosa, o que também permite a segregação das peças que possam estar com defeitos de fábrica, solicitando suas reposições.

\subsubsection{CURVA ABC}

Letti e Gomes (2014) enfatizam que curva $A B C$ é uma das formas mais fáceis e prática de solucionar problemas no gerenciamento de estoques, pela forma como ela traz os resultados, podendo-se trabalhar não somente com base nos números coletados nas organizações, como também na concepção de graus de conceito para os produtos.

RC: 99329

Disponível em: https://www.nucleodoconhecimento.com.br/administracao/catalogovirtual 
Segundo Pontes (2013), o método ABC apresenta-se como uma ferramenta gerencial eficiente e eficaz para a classificação dos itens componentes do estoque, sobretudo quanto a sua importância financeira.

A metodologia $A B C$ é uma ferramenta administrativa responsável por atribuir custos aos produtos baseados em atividades. Parte do princípio de que grande parte do custo total com matéria-prima concentra-se no gasto com poucos itens.

Em concordância com o Teorema de Pareto, $20 \%$ das contas representam $80 \%$ dos gastos e despesas realizados pela empresa, permitindo identificar os itens que merecem mais atenção e tratamento especial quanto à sua gestão e planejamento de compras. Desta forma, é possível concentrar os esforços para obter melhores resultados.

A Classificação ABC refere-se a três categorias, também chamadas de classes:

- Categoria A: itens que são muito importantes ou graves para o negócio.

- Categoria B: itens de média importância.

- Categoria C: itens relativamente sem importância.

A aplicação da curva $A B C$ na armazenagem possibilitará maior controle na gestão de estoque das semijoias, reduzirá os custos e proporcionará maior vantagem competitiva. Além disso, será possível reduzir o tempo de processo e movimentos que geram avarias nas semijoias, pois será aplicada uma contagem cíclica. Com isso, as divergências contábeis serão reduzidas, fazendo com que a empresa tenha agilidade em atender as demandas.

A curva $A B C$ concede um controle rigoroso do estoque a partir da prática da importância dos produtos, ou seja, levar como critérios os custos, demandas, prazos de entregas e alternativas de fornecimento de cada peça, para que haja a visão hierárquica dos mix de semijoias.

RC: 99329

Disponível em: https://www.nucleodoconhecimento.com.br/administracao/catalogovirtual 


\subsection{CICLO PDCA}

De acordo com Werkema (2014), o ciclo de PDCA é importante para as tomadas de decisões para assegurar o alcance das metas indispensáveis à continuidade da organização.

Para Couto e Marrash (2012, p. 2), o PDCA nas organizações tem como base os procedimentos seguidos na etapa "P" que determina onde se quer chegar impondo um planejamento eficaz e traçando um caminho para a situação desejada. Na sua implementação tem-se a prática do "D", trazendo a incerteza da realização de uma atividade importante, pois através de auditorias são encontradas muitas atividades fora do seu processo. Na etapa "C" é identificado algo que não está saindo conforme o planejado. Por fim, a etapa "A" é responsável por fechar o ciclo PDCA através de ações convincentes e com base nos insucessos nas etapas anteriores, garantindo a solução de problemas decorrentes e favorecendo um ciclo de melhoria contínua de um determinado processo.

O ciclo PDCA consiste em realizar planejamentos, para que a organização estabeleça metas e assegure que todos os colaboradores estarão envolvidos no processo de melhoria. A partir da identificação do problema é dado o seu grau de importância, ou seja, é realizada a observação do mesmo para que seja levantado as características do problema, isto é, a sua causa e as perdas que são geradas nele.

Por esse motivo é um método de controle e melhoria aconselhável que deve ser aplicado constantemente, e poderia ter sido aplicado desde o início do projeto das semijoias, o que teria trazido vantagens na qualidade, produtividade e diminuição de custos para a empresa.

O método PDCA pode ser utilizado para controlar os processos internos da organização para que seja garantido o alcance das metas estabelecidas, ou seja,

RC: 99329

Disponível em: https://www.nucleodoconhecimento.com.br/administracao/catalogovirtual 
utilizando as informações como princípio de orientação para as decisões que serão tomadas.

\subsubsection{W2H}

Conforme o autor Grosbelli (2014), a ferramenta 5W2H foi criada como uma ferramenta auxiliar na utilização do PDCA, mais precisamente na parte de planejamento, por profissionais da indústria automobilística do Japão. O objetivo básico desta fase do procedimento técnico é permitir que todas as atividades planejadas possam ser discutidas em grupo, antes da sua configuração no cronograma de ações administrativas de uma empresa ou instituição.

Para Polacinski (2012), a ferramenta 5W2H consiste em um plano de ação para atividades preestabelecidas que precisam ser desenvolvidas com a maior clareza possível, além de funcionar como um mapeamento dessas atividades. $O$ autor continua discorrendo e ressalta que o objetivo central da ferramenta $5 \mathrm{~W} 2 \mathrm{H}$ é responder a sete questões e organizá-las.

$\mathrm{O} 5 \mathrm{~W} 2 \mathrm{H}$ é um método que agiliza todos os processos de uma empresa, e pode ser projetado em uma planilha respondendo algumas perguntas-chave e a sua aplicação faz com que os prejuízos não sejam mais gerados e aumenta a vantagem competitiva.

Com isso, a falta de planejamento faz com que os processos gerem incalculáveis prejuízos e, para que isso não aconteça, a planilha $5 \mathrm{~W} 2 \mathrm{H}$ é útil por ser prática e pode ser realizada por organizações de qualquer porte, já que não é necessária uma equipe técnica especializada para realizar a sua construção, basta ter alguém que conheça o processo e saiba utilizá-la.

A ferramenta $5 \mathrm{~W} 2 \mathrm{H}$ pode ajudar na hora de definir os passos para mensurar 0 tempo, recursos e ações, pois a mesma consegue evidenciar as tarefas necessárias até que o objetivo seja alcançado pela empresa. Dessa forma, a ferramenta $5 \mathrm{~W} 2 \mathrm{H}$

RC: 99329

Disponível em: https://www.nucleodoconhecimento.com.br/administracao/catalogovirtual 
foi utilizada para realizar a verificação dos problemas que estavam ocorrendo no processo de vendas e no processo do estoque da empresa.

\subsection{MARKETING DIGITAL}

No que diz respeito à evolução do marketing ao longo das décadas, constatou-se que antes o mesmo era somente utilizado de forma funcional, ou melhor, utilizado na relação de venda de um produto ao cliente. Foi somente após várias evoluções, que o marketing de relacionamento surgiu visando melhorar a relação das organizações com os seus clientes. Nesse contexto, posteriormente o marketing digital surgiu para ampliar essa relação, mas de uma forma diferente, ou seja, utilizando-se da tecnologia para atrair um número maior de clientes (CRUZ e SILVA, 2014).

Como bem nos assegura Kotler (2012), fica claro que o objetivo de qualquer organização é agregar valor ao seu produto, de modo a satisfazer as necessidades e expectativas do cliente, gerando um sentimento positivo em relação ao produto.

Desta forma, o marketing digital é distinto do marketing tradicional, pois a internet é utilizada como estratégia de divulgação dos produtos das organizações, ou seja, os consumidores não necessitam realizar o deslocamento até a empresa, pois possuem o acesso dos produtos através da internet como, por exemplo, através dos catálogos virtuais. Por essa razão, o marketing digital tornou-se uma forma mais eficaz para a organização alcançar novos clientes, além de proporcionar a obtenção de resultados satisfatórios através de sua aplicação.

\subsubsection{CATÁLOGO DIGITAL}

Conforme o autor Napierala (2016), as atividades de propaganda são direcionadas para informar os clientes sobre o produto. A propaganda realizada através de vários meios de divulgação (jornais, rádio e televisão, diversos tipos de catálogos e folders), graças ao sistema de internet, recebeu o apoio do marketing direto e da internet.

RC: 99329

Disponível em: https://www.nucleodoconhecimento.com.br/administracao/catalogovirtual 
Para Sganzerlla (2013), podemos afirmar que o estudo sobre a decisão de compra do cliente é um processo contínuo, pois fica claro que o mercado e as necessidades do consumidor estão em constante mudanças, influenciadas por fatores sociais e situacionais.

O conceito de catálogo é de um produto de comunicação que busca atingir um público-alvo através da estratégia de visualização, onde se utilizam imagens que expressam os benefícios do produto ou serviço. Sendo assim, o catálogo virtual, também conhecido como catálogo digital é uma ferramenta de divulgação que consiste numa lista organizada, com intuito de agrupar e oferecer seus mix de produtos e serviços de maneira digitalizada ao seu cliente. O custo será menor, visto que não terá necessidade de impressão, sendo produzido uma única vez e depois atualizado periodicamente. Diante da dificuldade em utilizar métodos formais na venda de produtos, o catálogo virtual possui vantagens em sua utilização, pois quase toda a população utiliza as redes sociais e o comércio eletrônico tem crescido cada vez mais.

\section{MATERIAS E MÉTODOS}

De acordo com Aragão (2017), a metodologia diz respeito a uma preocupação com as ferramentas que irão constatar a busca pelo conhecimento e apresentar o resultado do que foi investigado. Já o método é a maneira que se busca narrar os procedimentos e as técnicas que são adequadas ao desenvolvimento da pesquisa.

Para trigueiro et al. (2014), a metodologia é representada como o estudo sobre os instrumentos que auxiliam o pesquisador a escolher qual será o método mais adequado e as técnicas que contribuirão para uma harmonia entre as abordagens teóricas e as ferramentas de pesquisa.

Elencaram-se neste estudo, técnicas de pesquisa bibliográfica e de caráter exploratório que contribuíram para definir os parâmetros de como deveria discorrer o

RC: 99329

Disponível em: https://www.nucleodoconhecimento.com.br/administracao/catalogovirtual 
caminho de nossa pesquisa para gerar conhecimento para a resolução de problemas e apontar as soluções que a empresa necessita.

\subsection{PROCEDIMENTOS METODOLÓGICOS}

Carvalho et al. (2019) afirma que a metodologia é o momento em que se deve ter atenção com as abordagens teóricas, pois aponta os procedimentos e as etapas usadas na realização da pesquisa. Já os procedimentos equivalem a uma análise descritiva nos mínimos detalhes de como se dará a pesquisa e os meios para aplicála.

Como nos assegura Severino (2014), método é o caminho para a produção do conhecimento científico, um cuidadoso plano de utilização, seguindo uma espécie de roteiro que envolve técnicas de pesquisa em função de um método e fundamentos epistemológicos que irão sustentar e justificar a metodologia aplicada.

Desenvolveram-se procedimentos metodológicos com base na pesquisa exploratória onde foi possível levantar informações de forma subjetiva e analisar casos semelhantes que já ocorreram no mercado, tendo como parâmetro o benchmarking que consiste em estudar as boas práticas de empresas referências no mercado.

\subsubsection{QUANTO À NATUREZA}

Segundo Marcondes et al (2017), a pesquisa aplicada tem por objetivo servir de apoio na tomada de decisão para que os gestores possam interpretar os dados através de indicadores de desempenho e melhorar os resultados operacionais, visando aumentar a competitividade em relação aos concorrentes.

Segundo Vergara (2016), a pesquisa aplicada encontra motivação na necessidade de resolver problemas presentes nas atividades das organizações, a fim gerar conhecimento para aplicação prática de soluções que respondam a uma demanda.

RC: 99329

Disponível em: https://www.nucleodoconhecimento.com.br/administracao/catalogovirtual 
Ressalta-se neste trabalho o aspecto de pesquisa aplicada, uma vez que, através dos métodos de investigação, teve-se como objetivo a implementação de ações para solução dos problemas apresentados pela empresa.

\subsubsection{QUANTOS AOS FINS}

Para Severino (2014), a pesquisa exploratória busca realizar o levantamento das informações de determinado objeto de estudo delimitando a sua área de atuação e servindo de preparação para a pesquisa explicativa.

Como bem nos assegura Lima (2018), a pesquisa exploratória tem por objetivo o levantamento de dados sobre um tema pouco estudado, recorrendo ao estudo bibliográfico para a delimitação do assunto e construção das hipóteses e similaridades com outros trabalhos.

Quanto aos fins, esta pesquisa exploratória foi realizada através de: levantamento de dados, questionários, entrevista, visitas no local, observação, análise e tabulação de dados dos elementos críticos do negócio.

\subsubsection{QUANTOS AOS MEIOS}

Mazucato et al. (2018) afirma que a consulta bibliográfica é um elemento básico para a pesquisa científica. Entende-se sobre esse momento quando o pesquisador vai em busca de todo o material debatido e delimita o seu objeto de estudo através das suas concepções teóricas de abordagens.

Para Vergara (2016), pode-se dizer que a pesquisa bibliográfica é um estudo coordenado com base em materiais publicados em diversas fontes, que servem como material analítico para qualquer tipo de pesquisa.

Quanto aos meios, adotou-se o método de pesquisa bibliográfica e documental, utilizando-se de dados secundários internos existentes na empresa e na observação das operações, recorreu-se à materiais bibliográficos com o propósito de nortear os 
estudos para compreensão dos dados a fim de conseguir algum proveito intelectual por meio da leitura.

\subsection{CARACTERÍSTICAS DA EMPRESA ESTUDADA}

A microempresa Minas d' Ouro Folheados Ltda foi criada em 2008 e tem sede em Manaus, Estado do Amazonas. Trata-se de uma empresa familiar que atua no ramo varejista de artigos de joalheria e que oferta seus produtos por meio de venda de kits de semijoias para revendedores cadastrados. Ou seja, a empresa cadastra e faz análise dos revendedores e após aprovação entrega o produto (semijoias) por consignação. Isto é, são entregues os kits de jóias com um prazo de três meses para quitação dos mesmos, com uma margem de comissão de $30 \%$ no que foi vendido.

Os modelos das coleções são inspirados nas principais tendências da moda em semijoias e leva em consideração: design, acabamento, moda, mercado e perfil das consumidoras. O portfólio de produtos abrange: pulseiras, anéis, brincos e cordões que são banhados a ouro, feito por encomenda segundo a necessidade dos clientes, sendo vendido em toda Manaus. A empresa não possui loja física, seu canal de vendas é somente através de revendedoras ou representantes comerciais externos, que ofertam porta a porta na casa dos clientes, ou o cliente entra em contato na empresa e logo é direcionado a um revendedor que o possa visitar em sua casa.

\section{RESULTADOS E DISCUSSÕES}

De acordo com Marcondes et al. (2017), uma das finalidades do diagnóstico é apresentar as causas efetivas dos problemas ou as suas condições através da coleta de dados e informações e, consequentemente, como os dados serão tratados e analisados.

Para Marconi e Lakatos (2017), na fase de interpretação dos resultados enfatiza-se a demonstração das evidências coletadas para confirmação ou refutação das 
hipóteses, bem como sua viabilidade, relevância e se o resultado encontra sustentação teórica.

Entende-se resultados e discussões como a parte subjetiva deste trabalho, responsável por discutir a comparação entre as variáveis e apresentar os fatos interpretados pelo autor da pesquisa.

\subsection{GRÁFICO DAS ÁREAS CRÍTICAS}

Por meio da análise de indicadores de desempenho das áreas funcionais realizada na referida empresa, avaliou-se os pontos que podem ser melhorados. Para tal foi necessário esquematizar as mudanças organizacionais necessárias para implementação das melhorias.

Gráfico 01: Medição de desempenho das áreas críticas

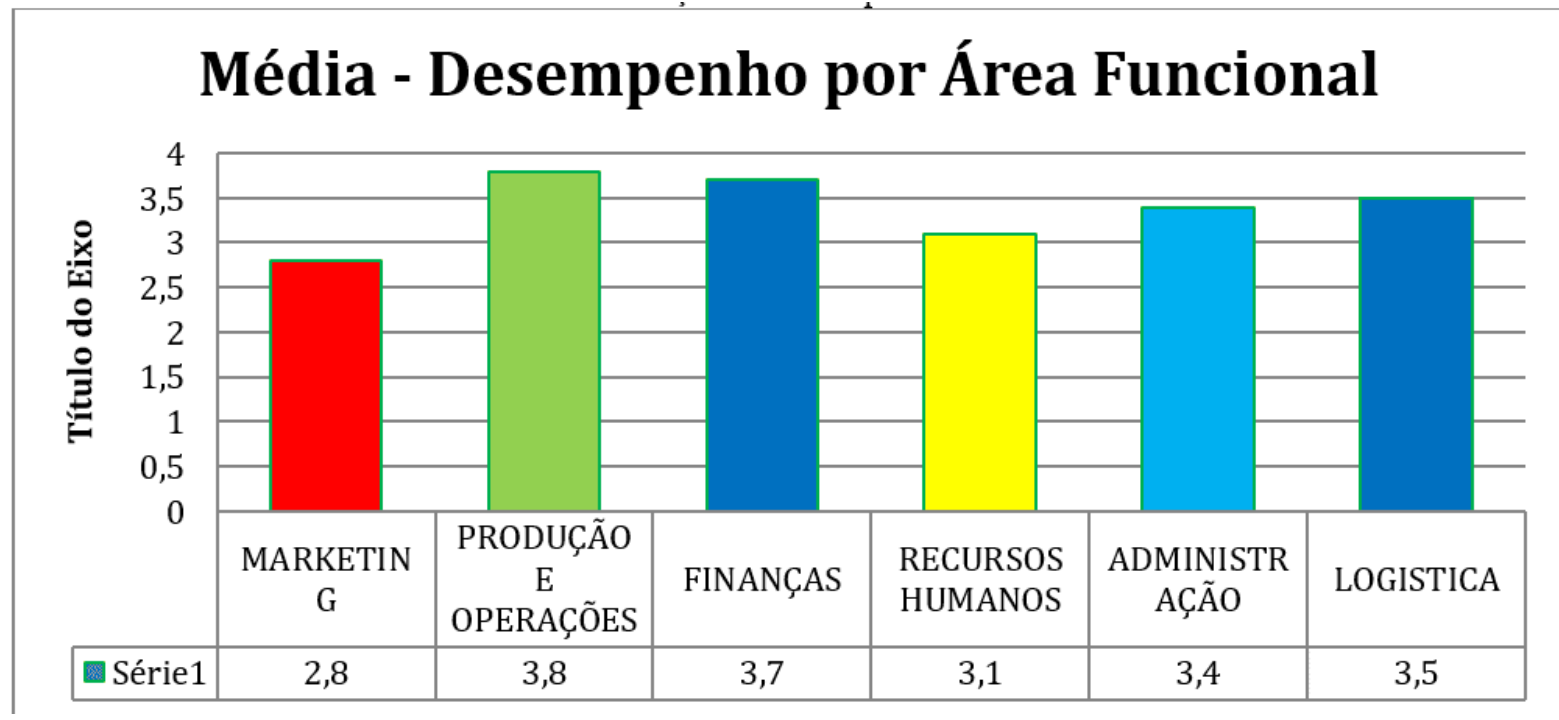

Fonte: Elaborado pelos autores com base na coleta de dados, 2021

Constata-se que a empresa tem a área de produção e operações, bem como de finanças como a de melhor desempenho; logística, administração e recursos humanos são áreas de desempenho médio. Já a de marketing é considerada a área

RC: 99329

Disponível em: https://www.nucleodoconhecimento.com.br/administracao/catalogovirtual 
mais crítica com percentual de 2,8, como podemos observar no gráfico 01 das áreas funcionais.

Quadro 01: Marketing

\begin{tabular}{|c|c|c|c|c|c|c|}
\hline \multicolumn{2}{|c|}{ ÁREA FUNCIONAL } & \multicolumn{5}{|c|}{ NÍVEL OU GRAU DE AVALIAÇÃO } \\
\hline \multicolumn{2}{|c|}{ MARKETING } & Ponto & Ponto & Ponto & Ponto & Ponto \\
\hline 1 & $\begin{array}{l}\text { Evidenciou-se vasta alternativa de } \\
\text { produtos no segmento de semi joias }\end{array}$ & & & $\mathrm{X}$ & & \\
\hline 2 & $\begin{array}{l}\text { Construiu-se políticas estruturadas } \\
\text { de promoções com representantes }\end{array}$ & & & $\mathrm{X}$ & & \\
\hline 3 & $\begin{array}{l}\text { Destaca-se a plataforma de e- } \\
\text { commerce processos otimizados de } \\
\text { buscas }\end{array}$ & & & & $\mathrm{X}$ & \\
\hline 4 & $\begin{array}{l}\text { Coletam-se informações sobre ticket } \\
\text { mensal de vendas dos } \\
\text { representantes }\end{array}$ & & & $\mathrm{X}$ & & \\
\hline 5 & $\begin{array}{l}\text { Verifica-se comunicação visual de } \\
\text { qualidade, criativa e inovadora }\end{array}$ & & & & $\mathrm{X}$ & \\
\hline 6 & $\begin{array}{l}\text { Realiza-se homologação de } \\
\text { representantes por região }\end{array}$ & & $X$ & & & \\
\hline 7 & $\begin{array}{l}\text { Avalia-se a taxa de conversão por } \\
\text { lote de consignação }\end{array}$ & & & $\mathrm{X}$ & & \\
\hline 8 & $\begin{array}{l}\text { Avalia-se taxa de rejeição dos } \\
\text { produtos por lote consignado }\end{array}$ & & $x$ & & & \\
\hline 9 & $\begin{array}{l}\text { Controla-se o tempo de } \\
\text { processamento do lote consignado }\end{array}$ & & & $\mathrm{X}$ & & \\
\hline 10 & Propaganda dos produtos incentiva & & & & & $X$ \\
\hline
\end{tabular}

RC: 99329

Disponível em: https://www.nucleodoconhecimento.com.br/administracao/catalogovirtual 


\begin{tabular}{|l|l|l|l|l|l|l|}
\hline \multicolumn{1}{|c|}{ o processo de compra } & 0 & 8 & 15 & 4 & 1 \\
\hline TOTAL $(\Sigma)$ & 0 & 0,8 & 1,5 & 0,4 & 0,1 \\
\hline MÉDIA POR GRAU (POR COLUNA) & 0 & & & & \\
\hline DESEMPENHO DA ÁREA $(\Sigma)$ TOTAL & 2,8 & & & & \\
\hline
\end{tabular}

Fonte: Elaborado pelos autores com base na coleta de dados, 2021

De acordo com a análise das áreas funcionais identificou-se que o setor de marketing possui o pior desempenho. Tão logo identificado os problemas, esse resultado sustentou a discussão de como um catálogo digital poderia contribuir para o processo de vendas e a captação de novos clientes, sendo que a internet é um meio de divulgação simples e de baixo custo. Portanto, foi proposto mudanças para a implementação de ações necessárias à empresa.

A ênfase foi a realização de um catálogo virtual para um pequeno nicho de mercado que a empresa tem competência de atender.

\subsection{QUADRO DAS AÇÕES INTERVENTIVAS}

Quadro 02: Ações interventivas

\begin{tabular}{|c|c|c|c|c|}
\hline & AÇÕES INTERVENTIVAS & CRONOLOGIA & DURAÇÃO & CUSTO \\
\hline 01 & $\begin{array}{l}\text { Implementação catálogo digital de } \\
\text { Vendas }\end{array}$ & Setembro/2021 & 15 dias & $\begin{array}{l}R \$ \\
1.550,00\end{array}$ \\
\hline 02 & $\begin{array}{l}\text { Estruturar um plano de } \\
\text { gerenciamento de estoque (curva } \\
\text { abc) }\end{array}$ & $\begin{array}{l}\text { Setembro } \\
/ 2021\end{array}$ & 20 dias & $\begin{array}{l}\mathrm{R} \$ \\
650,00\end{array}$ \\
\hline 03 & $\begin{array}{l}\text { Estruturar um treinamento para que } \\
\text { os revendedores aumentem os } \\
\text { tickets médios de vendas }\end{array}$ & Outubro /2021 & 90 dias & $\begin{array}{l}\mathrm{R} \$ \\
1.820,00\end{array}$ \\
\hline 04 & $\begin{array}{l}\text { Implementação de um inventário } \\
\text { cíclico e inventário rotativo }\end{array}$ & Outubro /2021 & 14 dias & $\begin{array}{l}\mathrm{R} \$ \\
1.365,00\end{array}$ \\
\hline
\end{tabular}

RC: 99329

Disponível em: https://www.nucleodoconhecimento.com.br/administracao/catalogovirtual 
Fonte: Elaborado pelos autores com base na coleta de dados, 2021

De acordo com a análise do desempenho das áreas críticas da organização, construiu-se o quadro de ações interventivas tendo como base a ferramenta de gestão $5 \mathrm{~W} 2 \mathrm{H}$, que nada mais é do que um checklist que auxilia na tomada de decisão e distribui responsabilidades, prazos e atividades.

\subsubsection{IMPLEMENTAÇÃO DE UM CATÁLOGO DIGITAL PARA A DIVULGAÇÃO DE PRODUTOS VAREJISTAS DE ARTIGOS DE JOALHERIAS}

O conceito de catálogo digital é de um produto de comunicação que visa atingir um público-alvo através da estratégia visual, onde se utilizam imagens que expressam as qualidades e beleza dos produtos. Sendo assim, o catálogo virtual, também conhecido como catálogo digital é uma ferramenta de divulgação que consiste numa lista organizada, com intuito de agrupar e oferecer seus mix de produtos, além de serviços de maneira digitalizada ao seu cliente. É muito mais barato do que um material impresso, pois é somente feito uma vez e depois atualizado periodicamente.

Quadro 03: Catálogo virtual

IMPLEMENTAÇÃO DE UM CATÁLOGO DIGITAL PARA DIVULGAÇÃO DE PRODUTOS VAREJISTAS DE ARTIGOS DE JOALHERIA.

\begin{tabular}{|l|l|l|}
\hline what & O que? & Catálogo digital de semijoias \\
\hline why & Por quê? & Para maior alcance e fidelização dos clientes \\
\hline where & Onde? & Minas de Ouro Folheados Ltda \\
\hline when & Quando? & Primeira semana de setembro de 2022 \\
\hline who & Quem? & Departamento Comercial \\
\hline how & Como? & Canal de Comunicação WhatsApp Business \\
\hline how much & Quanto? & $\mathrm{R} \$ 1.550,00$ \\
\hline
\end{tabular}

Fonte: Elaborado pelos autores com base na coleta de dados, 2021

RC: 99329

Disponível em: https://www.nucleodoconhecimento.com.br/administracao/catalogovirtual 
Com base nas informações disponíveis verificou-se a necessidade de criar um catálogo digital com informações relevantes dos produtos como fotos, preço e descrição do produto adquirido, para uma rápida comunicação com o cliente.

\subsubsection{PLANO DE GERENCIAMENTO DE ESTOQUE (CURVA ABC)}

A metodologia $A B C$ é uma ferramenta administrativa responsável pela gestão de estoques que busca atribuir custos aos produtos baseado em atividades, partindo do princípio de que nem todos os itens produzidos têm a mesma relevância.

De acordo com o Teorema de Pareto, $20 \%$ das contas representam $80 \%$ dos gastos e despesas realizados pela empresa, permitindo identificar os itens que merecem mais atenção e tratamento especial quanto à sua gestão e planejamento de compras. Desta forma, é possível concentrar os esforços para obter melhores resultados.

Quadro 04: Gerenciamento de estoque

\section{PLANO DE GERENCIAMENTO DO ESTOQUE}

\begin{tabular}{|l|l|l|}
\hline what & O que? & Plano de Gerenciamento de estoque \\
\hline why & Por quê? & Para verificar a acuracidade dos produtos no estoque \\
\hline where & Onde? & Minas de Ouro Folheados Ltda \\
\hline when & Quando? & Primeira semana de setembro de 2022 \\
\hline who & Quem? & Departamento almoxarifado \\
\hline how & Como? & Através do método curva abc \\
\hline how much & Quanto? & $\mathrm{R} \$ 650,00$ \\
\hline
\end{tabular}

Fonte: Elaborado pelos autores com base na coleta de dados, 2021

Verificou-se a necessidade de organizar a acuracidade do setor de almoxarifado para organizar o fluxo de informações e definir um estoque de segurança para atender os pedidos do catálogo digital de produtos, estabelecendo uma quantidade

RC: 99329

Disponível em: https://www.nucleodoconhecimento.com.br/administracao/catalogovirtual 
mínima e máxima de estocagem dos materiais auxiliares utilizados na produção e montagem dos kits de vendas.

\subsubsection{ESTRUTURAR UM TREINAMENTO PARA QUE OS REVENDEDORES AUMENTEM OS TICKETS MÉDIO DE VENDAS}

Analisando o mercado de artigos de joalheria em nosso país, pode-se perceber que seu segmento é caracterizado pelas grandes redes que possuem estruturas de lojas físicas, sendo marcas especializadas, e os pequenos varejistas autônomos definidos como comerciantes de jóias, legalizados ou não, que não possuem loja física.

Devido ao grande número de empresas informais que habitam no mercado, os pequenos varejistas praticam a chamada venda direta, em que vendedores autônomos fazem a famosa venda porta a porta por meio da demonstração de mercadorias.

Quadro 05: Plano de treinamento para técnicas de vendas

\section{TREINAMENTO PARA OS REVENDEDORES AUMENTAREM}

OS TICKETS MÉDIO DE VENDAS

\begin{tabular}{|l|l|l|}
\hline what & O que? & Treinamento para os revendedores \\
\hline why & Por quê? & Para aumentar os tickets médio de vendas \\
\hline where & Onde? & Minas de Ouro Folheados Ltda \\
\hline when & Quando? & Primeira semana de outubro de 2022 \\
\hline who & Quem? & Departamento comercial \\
\hline how & Como? & Através de reuniões, vídeos e manual do colaborador \\
\hline how much & Quanto? & $\mathrm{R} \$ 1.820,00$ \\
\hline
\end{tabular}

Fonte: Elaborado pelos autores com base na coleta de dados, 2021

A capacitação profissional é de suma importância em qualquer organização, sendo direcionada a aprendizagem de habilidades técnicas e específicas, e podendo ser

RC: 99329

Disponível em: https://www.nucleodoconhecimento.com.br/administracao/catalogovirtual 
realizada de maneira presencial ou a distância, de forma que seja um conteúdo padronizado e fixo que estabeleça diretrizes e formas de atuação que a empresa deseja seguir.

Espera-se através deste treinamento que os revendedores recebam ações de venda por meio da demonstração de mercadorias, através do marketing e da venda pessoal, oferecendo conforto e conveniência aos seus clientes.

\subsubsection{IMPLEMENTAÇÃO DE UM INVENTÁRIO CÍCLICO E INVENTÁRIO ROTATIVO}

Quadro 06: Etiquetas para identificação de materiais

\begin{tabular}{|l|l|l|l|}
\hline \multicolumn{3}{|l|}{ IMPLEMENTAÇÃO DE INVENTÁRIO CÍCLICO E INVENTÁRIO ROTATIVO } \\
\hline what & O que? & Controle mensal, trimestral e anual \\
\hline why & Por quê? & Para identificação de entrada e saída de produtos \\
\hline where & Onde? & Minas de Ouro Folheados Ltda \\
\hline when & Quando? & Primeira semana de outubro de 2022 \\
\hline who & Quem? & Departamento de almoxarifado \\
\hline How & Como? & Através da aquisição de um software de controle \\
\hline how much & Quanto? & $\mathrm{R} \$ 1.365,00$ \\
\hline
\end{tabular}

Fonte: Elaborado pelos autores com base na coleta de dados, 2021

A identificação de materiais no setor de estoque, bem como o seu correto acondicionamento é de suma importância para que a empresa tenha o mínimo de organização no momento da montagem e obtenha a padronização dos kits de semijoias para os revendedores.

\section{CONSIDERAÇÕES FINAIS}

De acordo com o objetivo proposto, acredita-se que, a aplicação da ferramenta WhatsApp Business, bem como o gerenciamento do estoque e as melhorias no

RC: 99329

Disponível em: https://www.nucleodoconhecimento.com.br/administracao/catalogovirtual 
processo de vendas contribuirão com o objetivo de atingir o público-alvo de maneira mais eficiente, estabelecendo uma melhor comunicação com o cliente e contribuindo com as soluções relevantes que agregam valor aos serviços oferecidos pela empresa.

Apesar das limitações que todo estudo apresenta, a inserção de recursos tecnológicos nos processos empresariais é apenas o ponto de partida para uma revolução nas metodologias de vendas online e, principalmente, na automatização desse processo. Assim, uma série de trabalhos ainda precisam ser feitos, inclusive para validação do método proposto neste artigo, em especial a criação e utilização de ferramentas de gestão e qualidade, além do marketing digital associados às melhorias tecnológicas empresariais e as redes sociais.

Diante dessa perspectiva, espera-se atingir os objetivos desta pesquisa com a aplicação dos seguintes indicativos: criação do catálogo virtual e aplicação das metodologias estratégicas $5 \mathrm{~W} 2 \mathrm{H}$ e curva $A B C$. Espera-se o aumento da produtividade no processo de vendas e a captação de novos clientes, além do aumento médio nos tickets de venda dos revendedores e melhor acuracidade no estoque.

Acredita-se que o resultado será atingido conforme a aplicação do catálogo virtual pelos revendedores para a captação de novos clientes e a intensificação contínua das vendas, hipótese que foi de encontro com a proposta de implementação apresentada nesta pesquisa, e os diversos processos de melhorias implementados através do quadro de ações interventivas que possibilitou o treinamento com revendedores, organização no estoque com curva $A B C$ e inventários cíclicos e rotativos, melhorando os indicadores de desempenho.

Assim, para elucidar as considerações finais deste estudo, resgatou-se a pergunta norteadora de como a implementação de um catálogo virtual pode contribuir para o processo de vendas e captação de clientes? Considera-se a ferramenta comercial WhatsApp Business como a plataforma responsável por estabelecer a comunicação

RC: 99329

Disponível em: https://www.nucleodoconhecimento.com.br/administracao/catalogovirtual 
entre a empresa e o público-alvo, através de seus catálogos de vendas e divulgação de produtos de maneira digital

Portanto, ao final deste estudo de caso, pautando-se na metodologia de pesquisa exploratória, conclui-se com base na literatura existente que o uso eficaz de ferramentas tecnológicas para fidelizar o cliente de maneira a cativá-lo, gerando mais visibilidade na divulgação dos produtos, por meio do catálogo digital corroborase na prática para influenciar o comportamento de compra do consumidor e que as plataformas digitais exercem influências positivas no marketing externo da organização.

\section{REFERÊNCIAS}

ARAGÃO, J. W. M. de.; NETA, M. A. H. Metodologia Científica. Superintendência de Educação a Distância, Faculdade de Educação, Salvador: UFBA, 2017. ISBN: 978-85-8292-131-9.

CARVALHO, L. O. R. et al. Metodologia científica: teoria e aplicação na educação a distância. Petrolina: PE, 2019. ISBN: 978-85-60382-91-0

COUTO, B. do A.; ROBERT, M. I. Gestão por processos: em sistemas de gestão da qualidade. Rio de Janeiro: Qualitymark, 2012.

CRUZ, C. A. B.; SILVA, L. L. Marketing digital: marketing para o novo milênio. Revista Científica do ITPAC, Araguaína, v.7, n.2, Pub.1, 2014. ISSN 1983-6708.

GROSBELLI, A. Proposta de melhoria contínua em um almoxarifado utilizando a ferramenta 5W2H. Universidade Tecnológica Federal do Paraná. Medianeira, 2014.

KOTLER, P. Administração de marketing. 14. ed. São Paulo: Pearson Education do Brasil, 2012. ISBN 978-85-8143-000-3

RC: 99329

Disponível em: https://www.nucleodoconhecimento.com.br/administracao/catalogovirtual 
KOTLER, P.; ARMSTRONG, G. Princípios de Marketing. 15ª ed. Editora Pearson Education, 2014.

LAKATOS, E. M. Fundamentos de metodologia científica. 8. ed. São Paulo: Atlas, 2017. ISBN 9788597010763.

LAZONICK, W. A. C. Managerial revolution: developing and utilizing productive resources. In: LAZONICK, W.; TEECE, D. J. Management innovation: essays in the spirit of Alfred D. Chandler Jr. New York: Oxford University Press Inc., 2012. p. 3-29.

LETTI, G. C; GOMES L. C. Curva ABC: Melhorando o gerenciamento de estoques de produtos acabados para pequenas empresas distribuidoras de alimentos. Update, Porto Alegre, v. 1, n. 2, p. 66-86, jul. /dez. 2014.

LIMA, P. G.; PEREIRA, M. C. (Orgs). Pesquisa científica em ciências humanas; uma introdução aos fundamentos e eixos procedimentais. Uberlândia, 2018.

MARCONDES, R. C. et al. Metodologia para trabalhos práticos e aplicados : administração e contabilidade. São Paulo: Editora Mackenzie, 2017.

MARTELLI, L; DANDARO, F. Planejamento e controle de estoque nas organizações. Revista Gestão Industrial, Ponta Grossa, v. 11, n.2, p.170-185, 2015.

MAZUCATO, T. (Org.) Metodologia da pesquisa e do trabalho científico. Penápolis: FUNEPE, 2018. ISBN 97885-93683-03-9

NAPIERALA, H. As vantagens competitivas do comércio eletrônico para empresas de pequeno e médio porte. Rev. FAE, Curitiba, v. 19, n. 1, p. 68-79, jan./jun. 2016.

POLESCHI, B. Estoques e Armazenagem. 1aㅡ ed. São Paulo: Érica, 2014. Cap. 3, p. 51-64.

RC: 99329

Disponível em: https://www.nucleodoconhecimento.com.br/administracao/catalogovirtual 
POLACINSKI, E. et al. Implantação dos 5 Ss e proposição de um SGQ para uma indústria de erva-mate. Gestão Estratégica: Empreendedorismo e Sustentabilidade - Congresso Internacional de Administração, 2012. Disponível em <http://www.admpg.com.br/2012/down.php?id=3037\%20\&q=1.> Acessado em 24 setembro 2021.

PONTES, A. E. L. Gestão de estoques: utilização das ferramentas curva abc e classificação xyz em uma farmácia hospitalar. Trabalho de Conclusão de Curso, UFPB, 2013.

SEVERINO, A. J. Metodologia do trabalho científico. 1르 ed. São Paulo: Cortez, 2013. ISBN 978-85-249-2081-3.

SGANZERLLA, S. Marketing de relacionamento. São Paulo: Anhembi Morumbi, 2013. IBSN 978-85-8344-027-7

TRIGUEIRO, R. de $M$. et al. Metodologia científica. Londrina: Editora e Distribuidora Educacional, 2014. 184 p. ISBN 978-85-68075-30-2

VERGARA, S. C. Projetos e relatórios de pesquisa em administração. 16a ed. São Paulo: Atlas, 2016. ISBN 978-85-970-0747-3.

WERKEMA, C. Ferramentas Estatísticas Básicas do Lean Seis Sigma Integradas ao PDCA e DMAIC. 1를 ed. Rio de Janeiro: Elsevier, 2014.

Enviado: Setembro, 2021

Aprovado: Outubro, 2021.

RC: 99329

Disponível em: https://www.nucleodoconhecimento.com.br/administracao/catalogovirtual 